\title{
Peertechz
}

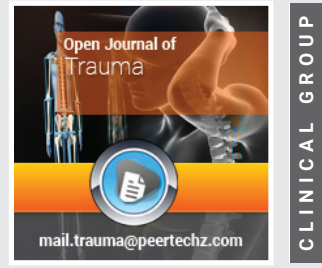

\section{An Investigation into the Vaccine for Covid-19 Within the United States}

\section{Femi Obasun*}

Research Institution, Researcher, Faculty, Liberty University, USA

Received: 14 December, 2020

Accepted: 28 December, 2020

Published: 29 December, 2020

*Corresponding author: Dr. Femi Obasun, PhD, DHA DBA, Research Institution, Researcher, Faculty, Liberty University, USA, Tel: 7575068004; Fax: 8049936163;

E-mail:drfemiobasun@researchinstitution.org

Keywords: Covid-19; Covid-20; Vaccine; Immunity; T-cells

https://www. peertechz.com

\begin{abstract}
This report looks into the current situation with regard to administering of Covid-19 vaccines within the United States and makes suggestions on how to aid the decision-makers' process. The study method is based on a review of existing data on Covid-19 vaccines and their effectiveness in eliminating the possibility of getting infected by the virus. The procedure utilizes the corresponding (incomplete) data that could theoretically be used in other decision-making methods. The review discovered that the information provided by the vaccine manufacturers is somewhat vague. The process entails predicting the future trend in Covid-19 mutation and the effectiveness of the existing vaccines in controlling the disease. The study interviewed 1200 vaccinated patients to give an opinion based on the patients.
\end{abstract}

Despite the skepticism with which Covid-19 was received, the disease has proven to be very resilient, affecting millions of people globally. In the midst of the confusion about the disease, Research Institution scientists were able to show how the disease was expanding in the United States and to make predictions about how the death toll would rise. The researchers described the disease strain's propagation, stating that it starts like the common flu, sharing its symptoms with the usual flu. However, instead of disappearing like other flu forms, the disease persisted and made the victims feel tired and hot. Another common symptom was a feeling of shortness of breath. Research Institution interviewed ten patients who had survived the disease, and they revealed that the disease affected their nervous systems and went on for about two weeks [1]. The disease even affected those who had generally been healthy all their lives. Research Institution described how the disease arrived in the USA and how it spread quickly to cover multiple states. According to the research, the patients had to stay in isolation from their loved ones to avoid infecting them with the deadly disease.

The article described how the virus originated from Wuhan, China, and moved to the United States by January 20, 2020. However, researchers are convinced the disease might have arrived earlier than that. What started as the small flu in a distant place managed to spread beyond China into other parts of the world, including the US [1]. Thanks to research and development, different versions of the Covid-19 vaccine have been developed and are undergoing human trials. Some have produced up to $95 \%$ effectiveness against the current strain of the virus. However, the 2020 summer made the Covid-19 strain weaker and less fatal. The number of deaths resulting from the virus was projected to be much higher than the Spanish flu epidemic [1]. However, due to the warm temperatures during summer, the disease trait has not reached its predicted fatality rate because the virus was made weaker. With the onset of the winter of 2020, the covid-19 virus is expected to become much stronger during December 2020, January, and February 2021. According to data obtained from Researchinstitution.org, cold temperatures of winter are expected to make the virus strain to mutate and become more dangerous [2]. Even though vaccines have been manufactured and have already passed the initial stages of the human trial, they may not be effective against the mutated version of Covid-19, which is expected to be named the Covid- 20 by scientists.

\section{Results and discussion}

According to an interview conducted by Research Institution, 1200 were supposed to take the Covid-19 vaccine between August and September 2020; the vaccine is proving strong against the Covid-19 virus [2]. However, the manufacturers and scientists have not considered the possible mutation of the virus so that it may become stronger during the cold 
temperatures in the winter months of December, January, and February. Research Institution originally published the findings of the mutation of Covid-19 into a more potent strain that could defeat the vaccines that have been manufactured. The research conducted by the Research Institution has shown that the current vaccines could be ineffective since the disease is most likely going to mutate into a stronger trait leading to reinfections at a higher rate than the one that has already been experienced.

There are currently three COVID-19 vaccines that are undergoing safety tests. There are some national regulatory authorities that have already given the authorization to use these drugs in vaccinating people against the deadly virus. None of the vaccines have received the WHO EUL/PQ authorization. However, it is expected that the Pfizer -BioNTech vaccine will be assessed by WHO before the end of 2020 and the other vaccine candidates are to follow suit soon after. The other two candidates include Moderna and AstraZeneca vaccines. However, only the AstraZeneca has study results published in peer reviewed articles. Many manufacturers are working around the clock to find the most effective Covid-19 vaccine and they are being submitted to regulatory authorities seeking approval. AstraZeneca and Janssen's Covid-19 vaccines were still in their phase 3 trials by the end of November 2020 .

Our research findings indicate that those who received the Pfizer vaccine experience less side effects of the drug compared to other drugs. The results also indicate that the Pfizer is more deserving of WHO approval than the other candidates as it enhances the individual's immunity more significantly. Of the 1200 interviewed respondents, about $70 \%$ were confident that they were now safe from the Covid-19 virus. However, when asked if they have any idea about the Covid-19 virus mutation, only 15 individuals agreed that they had heard about it. None of the respondents were aware of the relationship between Covid-19 severity and the summer or winter seasons.

The occurrence of reinfection can only be confirmed through a gold-standard confirmation of SARS-CoV-2 reinfection. This confirmation will require the detection of the virus within two different time periods and conducting genetic sequencing to confirm that the virus is actually mutating. In October 2020, the CDC developed a common investigation protocol that is to be used in investigating the suspected SARS-CoV-2 reinfection. It is meant to support a common public health study into the suspected resurgence of Covid-19 reinfections in various jurisdictions [3]. To confirm that reinfection has actually taken place, the researchers must conduct advanced laboratory diagnostics and build upon the plan to implement the protocol. It is also possible to develop a locally adapted version of the protocol, but the specimens have to support the laboratory networks. Once the data has been collected through the use of the CDC developed protocol, it will be used to identify potential reinfection cases and promote the advancement of the understanding of the SARS-CoV-2 epidemiology and make informed public health response in the future. Patient symptomology and epidemiologic links could provide the required laboratory-based parameters for differentiating the possibility of SARS-CoV-2 reinfection from the persistent viral carriage. However, it would be impossible to confirm reinfection in the absence of clinical specimens that were obtained during the first COVID-19 illness.

Many other human coronaviruses (HCoVs) have been known to lead to reinfections. According to a study in Kenya, between 4 and 21 percent of people infected by the endemic coronaviruses like $\mathrm{NCoV}-\mathrm{NL} 63, \mathrm{HCoV}-229 \mathrm{E}$ and $\mathrm{HCoV}-0 \mathrm{C} 43$ have had two or more infection episodes with a similar virus species within a period of six months. In another study in which a rise in antibodies was used as a proxy for reinfections, it was discovered that reinfections could actually take place within a median of six months but could take place as early as half a year after the first infection. There is, however, minimal information about the durability of immunity to SARS-CoV-2. For instance, it has been documented in South Korea that the COVID-19 cases that had been undetectable by the RT-PCR could later be tested and found to be positive by the same RT-PCR within a 35-day time span. This was attributed to the presumption that there were incomplete or defective viral genomes, which means that reinfection was undetectable within the time frame. To establish a common understanding of Covid-19 reinfections, CDC [3] recently developed a standard investigation protocol to identify cases with a high index of suspicion for reinfection. The CDC also provided suggestions for paired specimen testing.

In light of the expected reinfection by the mutated Covid-20 virus, it is essential to consider the safety measures suggested by Obasun [2]. According to the research done by Research Institution, there is a need to restrict movement and discover vaccines and prescription medication for those already infected. The Covid-19 vaccine discovery has been a significant breakthrough, but the possibility of Covid-20 is quite worrying. The case is even more bizarre considering the immunity of the people in the United States. According to Obasun [2], the immunity in the US is much lower than that in China, from where the disease originated. This is mainly because of Americans' health conditions, including diabetes, obesity, and other immunity-lowering conditions.

Through research, it has been discovered that people often develop antibodies to particular diseases after they have been exposed to such illnesses, which can help them avoid becoming re-infected by the same disease trait (Obasun, 2020b) [2]. People in tropical areas are often exposed to tropical diseases, which are useful in helping them accumulate T-cells. The T-cells are responsible for helping the body to fight off infections like malaria. The coronavirus has, however, proven much stronger than the T-cells. With very low levels of T-cells and very low winter temperatures, it is expected that Americans could suffer a major blow from the mutated version of Covid-19.

The Covid-19 has infected more than 12 million people globally and has led to more than half a million deaths. The disease has also caused an economic toll of trillions of dollars. The disease has affected some of the most vulnerable members of society, including those aged 65 years and more, people who are economically deprived, and those living with underlying health conditions. Considering its effects and the rate at which 
it is still spreading, there is an urgent need to make vaccines available to the public to help eliminate the complications and deaths that are taking place as a result of the transmission of the disease.

Scientists and major research institutions have been conducting extensive research to find an effective vaccine against the disease. An mRNA SARS-CoV-2 vaccine was recently developed and successfully taken through a phase 1 trial in which the researchers were interested in the immunogenicity of the vaccine [4]. The trial involved forty-five healthy adults aged between 18 and 55 years [5]. The individuals were injected with the candidate vaccine at different doses, $25 \mu \mathrm{g}, 100 \mu \mathrm{g}$, or $250 \mu \mathrm{g}$ [6], which was given in the form of two vaccinations 28 days apart. It is remarkable how quickly the vaccine has been developed, and its effectiveness is promising.

\section{Conclusion}

As people continue to enroll for phase 3 of the SARS-CoV-2 vaccine and the target enrolments have been achieved, there is hope that there could be an end to the COVID-19 pandemic. It has been established that no approvals will be made until the vaccines are proven to be safe and effective. However, the current tests have not even come close to ensuring that a vaccine is both safe and effective. This makes it quite doubtful whether there is to be any further breakthrough. Considering the projections made by Research Institution that the virus could be mutating to become more severe at the end of 2020 and the beginning of 2021 , the possibilities are even slimmer. The disease could become more deadly and lead to even more infections and deaths in 2021 than it has been in the past [7]. Therefore, there is a need to exercise more caution, and research needs to be more rigorous to discover better ways of dealing with a mutated version of the virus.

\section{References}

1. Obasun F (2020) Staying Safe in Light of the Impending COVID-20. Journal of Humanities, Arts and Social Science 4: 109-111. Link: https://bit.ly/38luPT4

2. Obasun F (2020) The Human Corona-virus Circulation in the USA, 2019-2020 Link: https://bit.ly/3403wG9

3. CDC (2020) Coronavirus Disease 2019 (COVID-19). Common Investigation Protocol for Investigating Suspected SARS-CoV-2 Reinfection. Link: https://bit.ly/3hnWDAc

4. Heaton PM (2020) The Covid-19 Vaccine-Development Multiverse. N Engl J Med 2020 383: 1986-1988. Link: https://bit.ly/2JupFIm

5. Doshi $\mathrm{P}$ (2020) Will covid-19 vaccines save lives? Current trials aren't designed to tell us. BMJ 371. Link: https://doi.org/10.1136/bmj.m4037

6. Kagina B (2020) COVID-19 vaccine trials in Africa: what's promising, and what's problematic. Link: https://bit.ly/3nTyUdJ

7. Mintzes B, Lexchin J, Chiu K, Parker L (2020) Should Australians be worried about waiting for a COVID vaccine when the UK has just approved Pfizer's? Link: https://bit.ly/2WRs0JX

\section{Discover a bigger Impact and Visibility of your article publication with}

\section{Peertechz Publications}

\section{Highlights}

* Signatory publisher of ORCID

* Signatory Publisher of DORA (San Francisco Declaration on Research Assessment)

* Articles archived in worlds' renowned service providers such as Portico, CNKI, AGRIS, TDNet, Base (Bielefeld University Library), CrossRef, Scilit, J-Gate etc.

* Journals indexed in ICMJE, SHERPA/ROMEO, Google Scholar etc.

* OAI-PMH (Open Archives Initiative Protocol for Metadata Harvesting)

* Dedicated Editorial Board for every journal

* Accurate and rapid peer-review process

* Increased citations of published articles through promotions

* Reduced timeline for article publication

Submit your articles and experience a new surge in publication services (https://www.peertechz.com/submission).

Peertechz journals wishes everlasting success in your every endeavours.

Copyright: (c) 2020 Obasun F. This is an open-access article distributed under the terms of the Creative Commons Attribution License, which permits unrestricted use distribution, and reproduction in any medium, provided the original author and source are credited. 